\title{
Ecoefficiency of Intensive Agricultural Production and Its Influencing Factors in China: An Application of DEA-Tobit Analysis
}

\author{
Heyuan You' ${ }^{1}$ and Xiaoling Zhang ${ }^{2}$ \\ ${ }^{1}$ College of Public Management, Zhejiang University of Finance and Economics, Hangzhou 310000, China \\ ${ }^{2}$ Department of Public Policy, City University of Hong Kong, Kowloon 999077, Hong Kong \\ Correspondence should be addressed to Heyuan You; youheyuan@gmail.com
}

Received 27 November 2015; Accepted 15 February 2016

Academic Editor: Kannan Govindan

Copyright ( $\odot 2016$ H. You and X. Zhang. This is an open access article distributed under the Creative Commons Attribution License, which permits unrestricted use, distribution, and reproduction in any medium, provided the original work is properly cited.

\begin{abstract}
The excessive use of inputs per unit of agricultural land poses a great threat to ecological sustainability. Using an input-oriented data envelopment analysis (DEA) model, this study analyzes ecoefficiency of intensive agricultural production in 31 provinces in China. The results show that the total efficiency of only six provinces can be considered fully efficient and that scale efficiencies are generally lower than technical efficiencies. Then, the spatial distribution of ecoefficiency is analyzed. The findings demonstrate that the provinces whose ecoefficiencies are maximal are primarily located in western China. The technical efficiencies in the western region are better than those in the eastern and middle regions. Imperfect scale efficiencies are distributed across all three regions. Furthermore, using the Tobit model, an analysis of the factors that influence ecoefficiency shows that the variables of farmland area per capita (FA), income per capita (IC), population per household (PH), and population burden coefficient (PB) have statistically significant impacts on total efficiency. The distinct effects of the variables on total efficiency are caused by their differential effects on technical efficiency and scale efficiency. Finally, suitable policies designed to improve ecoefficiency are proposed according to the local circumstances of each of the three regions.
\end{abstract}

\section{Introduction}

Although it accounts for only 7 percent of the worldwide total, agricultural land in China feeds 22 percent of the world's population. Grain production increased on average by $3 \%$ annually in the past 40 years in China [1]. The increased yields resulted primarily from greater inputs of labor, pesticides, chemical fertilizers, and energy $[2,3]$. The increase in agricultural output has provided enough food to reduce hunger and improve human nutrition in China [4]. However, the excessive use of pesticides and chemical fertilizers creates various environmental problems, including soil erosion and water pollution $[5,6]$. Meanwhile, these environmental problems pose great threat to human health and the sustainable household livelihoods [7-9].

Despite agricultural land being a highly valuable resource for achieving food security in China, high quality agricultural land is continuously converted into construction land due to rapid urbanization, industrialization, and poor government regulation [10-15]. Therefore, intensive agriculture has been widely advocated as a struggle to feed the increasing population considering the limited agricultural land [16]. The key point of intensive agriculture is the choice of a suitable input intensity that achieves an adequate desired production without increasing, and, more preferably, decreasing, environmental damage [17]. Ecoefficiency is a widely used indicator that describes the capability to achieve desired production and at the same time cause minimal environmental damage [18]. However, few studies have analyzed the ecoefficiency of agricultural production, especially with regard to intensive agriculture. Therefore, an ecoefficiency assessment is selected in this study to integrate ecological impacts into an analysis of intensive agricultural production in China and thereby inform certain changes in agricultural production that could help achieve sustainable farming. 
This study uses a DEA approach to measure the ecoefficiency of intensive agricultural production in China. However, DEA has limited use for identifying the factors that influence efficiency. In order to conduct a further exploration of the factors that influence ecoefficiency, this study conducts the analysis over two stages. The first stage estimates the ecoefficiency of intensive agricultural production by DEA. The second stage analyzes potential underlying factors that influence the ecoefficiency by Tobit model. We specifically attempt to (1) define the ecoefficiency which is suitable for this study; (2) develop the Charnes-Cooper-Rhodes (CCR) and Banker-Charnes-Cooper (BCC) models for analyzing ecoefficiency; (3) discuss input-output variables applied in the ecoefficiency assessment of intensive agricultural production and show the results of a case study pertaining to total efficiencies, technical efficiencies, and scale efficiencies in 31 provinces in China; (4) analyze the influencing factors based on the Tobit model; and (5) provide some policies designed to improve ecoefficiency in China.

\section{Literature Review}

Ecoefficiency has been proposed as one feasible method for exploring sustainable development strategy [19]. Increasing literature has reported the applications of ecoefficiency into environmental studies. Ecoefficiency of 24 power plants in Europe and intensification scenarios for milk production in New Zealand were evaluated by treating pollutants as the inputs [20, 21]. Ecoefficiency analysis for regional industrial systems in China was performed using data from 30 provinces [22]. Ecoefficiency indicators were developed to design a framework for implementing cleaner production initiatives for the Canadian food and beverage industry [23]. However no agreement has been reached on the definition of ecoefficiency, since the ecoefficiency is a context-specific concept [20]. One important approach in the ecoefficiency literature is to define ecoefficiency as a ratio: ecoefficiency = economic value added/environmental damage [18]. But this definition is not suitable for DEA analysis since it neglects the resources which are used in the production process. In this paper, the ecoefficiency is defined as the capability that creates the highest economic value with lowest ecological damage. Therefore, it is the ratio of a weighted sum of the outputs (desired products, desired services, and ecological damage) to a weighted sum of the inputted resources [24]. One important implication of outputs is that the growth of desired products and services should be delinked as much as possible from harmful outputs including pollution and waste.

The methods used to assess the ecoefficiency include ratio calculation between economic value added and environmental damage, cost-benefit analysis, life cycle assessment, and data envelopment analysis [18, 30, 31]. Because the ecoefficiency is defined as the ratio including multiinput and multioutput in this paper, the methods are not suitable for assessing the ecoefficiency in this study except DEA. DEA which is a nonparametric methodology is an important method for evaluating the relative efficiency of decision-making units (DMUs) and is widely used to solve the efficiency related problems based on multi-input and multioutput production [32]. One of the obvious advantages of DEA is that it does not make any prior assumptions on the relationships between input and output variables. The complicated functional relationship between inputs and outputs in agricultural production process is not fully understood. Therefore, the DEA should be a suitable tool to assess the ecoefficiency of intensive agricultural production. Previous analyses performed using DEA models include a cross-country comparison of the ecoefficiencies of cement industries, an assessment of the ecoefficiency of pesticides, and a selection of transport modes based on ecoefficiency [33-35]. The ecoefficiency of the agricultural sector also has attracted the attention in past years. Ecoefficiency of olive farming at farm level in the rural areas of Andalusia in Spain was quantified by using DEA and pressure distance functions [36]. In addition, an input-orientated data envelopment analysis framework was developed to assess the ecoefficiency of 30 OECD countries [37]. Because rapid economic growth tends to correlate with environmental problems, increasing interest has been demonstrated in examining whether ecoefficiencies are sufficient for achieving sustainable development $[18,38]$.

\section{Methods}

3.1. Ecoefficiency Assessment Using DEA. The ecoefficiency assessment of intensive agricultural production involves two DEA models, including the CCR model and the BCC model, which defines efficiency as a ratio of a weighted sum of outputs to a weighted sum of inputs. The CCR model, which assumes constant returns-to-scale (CRS), measures the total efficiency of a DMU, and the BCC model, which assumes variable returns-to-scale (VRS), measures the technical efficiency of a DMU. The input-oriented or output-oriented CCR and BCC models, selected according to the purpose of production, are usually employed. The ideal intensive agricultural production level can be characterized as one that uses the lowest quantity of inputs to produce a given level of output. Therefore, an input-oriented CCR model and an input-oriented BCC model are employed to assess the ecoefficiency of intensive agricultural production in this study.

We assume there are $n$ homogeneous provinces, and each province consumes $m$ inputs and produces $s$ outputs. The input-oriented CCR model in ratio form can be summarized as follows [39]:

$$
\begin{array}{ll}
\operatorname{Max} & H_{p}=\frac{\sum_{j=1}^{s} U_{j} Y_{j p}}{\sum_{i=1}^{m} V_{i} X_{i p}} \\
\text { S.T. } & \frac{\sum_{j=1}^{s} U_{j} Y_{j k}}{\sum_{i=1}^{m} V_{i} X_{i k}} \leq 1 \quad \forall k, k=1, \ldots, n \\
& U_{j} \geq \varepsilon \geq 0 \quad \forall j, \quad j=1, \ldots, s \\
& V_{i} \geq \varepsilon \geq 0 \quad \forall i, \quad i=1, \ldots, m,
\end{array}
$$

where $H_{p}$ is total efficiency of the $p$ th province, $X_{i k}$ and $Y_{j k}$ are the $i$ th input and the $j$ th output corresponding to the $k$ th province, respectively, $V_{i}$ and $U_{j}$ are the $i$ th input 
weight and the $j$ th output weight, respectively, and $\varepsilon$ is a nonArchimedean infinitesimal variable.

Using a linear transformation, the input-oriented CCR model in dual form is expressed as follows:

$$
\begin{array}{lc}
\text { Min } & \theta_{p}-\varepsilon\left[\sum_{i=1}^{m} S_{i}^{-}+\sum_{j=1}^{s} S_{j}^{+}\right] \\
\text {S.T. } & \theta_{p} X_{i p}-\sum_{k=1}^{n} \lambda_{k} X_{i k}=S_{i}^{-} \\
& \sum_{k=1}^{n} \lambda_{k} Y_{j k}-Y_{j p}=S_{j}^{+} \\
& \lambda_{k} \geq 0, S_{i}^{-} \geq 0, S_{j}^{+} \geq 0,
\end{array}
$$

where $\theta_{p}$ is the multiplier of the $p$ th province, $\lambda_{k}$ is the weight of reference set of the $k$ th province, $S_{i}^{-}$is the input excess of the $i$ th input, and $S_{j}^{+}$is the output shortfall of the $j$ th output.

The input-oriented BCC model which assesses the technical efficiency using linear program is obtained by adding the intercept in (1) and the convexity constraint $\sum_{i=1}^{m} V_{i} X_{j p}=1$ [40]. Using a linear transformation, the input-oriented BCC model with the constraint $\sum_{k=1}^{n} \lambda_{k}=1$ in dual form is expressed as follows:

$$
\begin{array}{ll}
\text { Min } & \theta_{p}-\varepsilon\left[\sum_{i=1}^{m} S_{i}^{-}+\sum_{j=1}^{s} S_{j}^{+}\right] \\
\text {S.T. } & \theta_{p} X_{i p}-\sum_{k=1}^{n} \lambda_{k} X_{i k}=S_{i}^{-} \\
& \sum_{k=1}^{n} \lambda_{k} Y_{j k}-Y_{j p}=S_{j}^{+} \\
& \sum_{k=1}^{n} \lambda_{k}=1 \\
& \lambda_{k} \geq 0, S_{i}^{-} \geq 0, S_{j}^{+} \geq 0 .
\end{array}
$$

Finally, the measure of scale efficiency for ecoefficiency of intensive agricultural production in the $p$ th province is computed as the quotient between total efficiency and technical efficiency:

$$
\mathrm{SE}_{p}=\frac{H_{p}}{Z_{p}}
$$

where $Z_{p}$ is technical efficiency of the $p$ th province.

3.2. Tobit Model Analysis. Ecoefficiency has been criticized for excluding economic rationale and lacking connections to environmental policy instruments. This is because most of the previous studies treat DEA as a black-box to measure ecoefficiency. Explanation of differences in ecoefficiency analysis is important because inefficiency in environmental performance implies the existence of negative factors, which is difficult to justify in the traditional framework of environmental economics. It also connects ecoefficiency to environmental regulation and innovations in technology which is very relevant for policy purposes. The primary statistical method to analyze the linear relationships between variables is ordinary least squares (OLS). One important assumption for OLS is that the expected value of the residuals is zero. Violating this assumption, when applying OLS on censored or truncated data, it will not guarantee that the expected value of the residuals is necessarily zero. Therefore the parameter estimate is biased [41]. The values of ecoefficiency estimated by DEA are limited and lie in the unit interval $[0,1]$. The Tobit model proposed by Tobin [42] is suitable for solving problems with limited dependent variables. Previous studies have applied the Tobit model to analyze explanatory variables to explore the determinants of truncated variables, such as environmental technological efficiency, health production efficiency, efficiency of worldwide railway companies, and efficiency of government spending on health [43-46]. Consequently, the Tobit model can be employed to help in the discovery of factors restricting ecoefficiency.

A maximum likelihood estimation is used to evaluate parameters in the Tobit model in this study. The standard Tobit model is expressed as follows [42]:

$$
\begin{aligned}
y_{i}^{*} & =\beta^{T} x_{i}+\mu_{i} \quad \mu_{i} \sim\left(0, \sigma_{u_{i}}^{2}\right), i=1,2,3, \ldots, n, \\
y_{i} & = \begin{cases}y_{i}^{*}, & y_{i}^{*}>0 \\
0, & y_{i}^{*} \leq 0,\end{cases}
\end{aligned}
$$

where $i$ is the $i$ th province (DMU), $y_{i}^{*}$ is the latent dependent variable, $y_{i}$ is the limited sample value, $x_{i}$ is the $K \times 1$ matrix of the explanatory variables, $\beta^{T}=\left(\beta_{1}, \beta_{2}, \beta_{3}, \ldots, \beta_{k}\right)$, and $\mu$ is the error term, which submits to $N\left(0, \sigma_{u_{i}}^{2}\right)$.

\section{Ecoefficiency Analysis of Intensive Agricultural Production}

4.1. Input-Output Variables. Input-output variables of agricultural production should be identified by using DEA to evaluate ecoefficiency. However, agricultural production is a complex system of plant and animal production with multiple inputs and outputs. Table 1 summarizes the inputs and outputs reported in previous studies [25-29]. The input variables and output variables selected herein reflect the purpose of this study. The ecoefficiency analysis of agricultural production aims at creating improved outputs and using fewer resources while discharging less pollution and waste. Intensive agricultural production is characterized by the high use of inputs relative to a given area of agricultural land. Therefore, the input variables that represent the characteristics of intensive agricultural production are defined as the inputs used per unit of agricultural land area. Although various inputs were selected in previous studies, this study only focuses on the five critical inputs in agricultural production: labor, agricultural machinery, pesticides, chemical fertilizers, and diesel oil. Consequently, the input variables chosen are labor intensity, 
TABLE 1: Summary of inputs and outputs selected in previous studies.

\begin{tabular}{|c|c|c|c|c|}
\hline Researcher & Main concept & Research object & Inputs & Outputs \\
\hline \multirow{7}{*}{ Ray and Ghose (2014) [25] } & \multirow{7}{*}{ Production efficiency } & \multirow{7}{*}{ Agriculture in India } & (1) Land & (1) Food grains \\
\hline & & & (2) Fertilizers & (2) Nonfood grains \\
\hline & & & (3) Irrigated area & \\
\hline & & & (4) Pump sets & \\
\hline & & & (5) Tractors & \\
\hline & & & (6) Electricity & \\
\hline & & & (7) Labor & \\
\hline \multirow{5}{*}{ Ma and Feng (2013) [26] } & \multirow{5}{*}{ Efficiency } & \multirow{5}{*}{ Agriculture in China } & (1) Labor & $\begin{array}{l}\text { (1) Gross value of } \\
\text { agricultural output }\end{array}$ \\
\hline & & & (2) Land & \\
\hline & & & (3) Machinery & \\
\hline & & & (4) Fertilizer & \\
\hline & & & (5) Draft animals & \\
\hline \multirow{5}{*}{ Picazo-Tadeo et al. (2011) [27] } & \multirow{5}{*}{ Farming ecoefficiency } & \multirow{5}{*}{ Spanish farmers } & (1) Seeds & (1) Sales \\
\hline & & & (2) Nitrogen & (2) Coupled subsidies \\
\hline & & & (3) Phosphorus & (3) Agrienvironmental \\
\hline & & & (4) Pesticides & \\
\hline & & & (5) Energy & \\
\hline \multirow{3}{*}{ Chih-Hai et al. (2010) [28] } & \multirow{3}{*}{ Efficiency } & \multirow{3}{*}{ Agriculture in China } & (1) Agricultural labor & $\begin{array}{l}\text { (1) Gross value added of } \\
\text { farming }\end{array}$ \\
\hline & & & (2) Agricultural machinery & \\
\hline & & & (3) Cultivated land & \\
\hline \multirow{4}{*}{ Nkamleu (2004) [29] } & \multirow{4}{*}{ Efficiency } & \multirow{4}{*}{ Agriculture in Africa } & (1) Labor & $\begin{array}{l}\text { (1) Aggregated outputs of } \\
\text { agricultural production }\end{array}$ \\
\hline & & & (2) Agricultural land & \\
\hline & & & (3) Fertilizer & \\
\hline & & & (4) Tractors & \\
\hline
\end{tabular}

agricultural machinery use intensity, pesticide use intensity, chemical fertilizer use intensity, and diesel oil use intensity.

Agricultural production creates both beneficial outputs and harmful outputs. According to previous studies [25, 27], gross output value is usually used to represent beneficial outputs, and this value is also used in this study in a similar manner. However, pollution and waste, such as ammonia nitrogen $\left(\mathrm{NH}_{3}-\mathrm{N}\right)$, total nitrogen $(\mathrm{TN})$, and total phosphorus (TP), are also outputs, as byproducts, of farming practices, and their presence has made it considerably difficult to realize zero emissions from agricultural production under state-ofthe-art techniques. The excessive use of chemical fertilizers leads to a surplus of nitrogen $(\mathrm{N})$ and phosphorus $(\mathrm{P})[47,48]$. The decrease in agricultural labor aggravates the excessive use of chemical fertilizers. Due to the decreases in agricultural labor, the peasant households increase chemical fertilizers to maintain high yields [49]. Currently, machines whose power is supplied by diesel oil cannot be widely used to spread chemical fertilizer. In many areas, the primary labor includes the elderly, children, and women, who spread chemical fertilizer by hand [50]. Therefore, the wide application of agricultural machinery which adopts advanced agricultural technology such as fertilizer deep placement technology and balanced fertilization technology can control the excessive use of chemical fertilizers. However, in standard CCR and BCC models, the direct reduction of the undesirable harmful outputs is not allowed. The method that transforms harmful output variables into new variables similar to beneficial output variables can solve this problem. It is widely used to assess ecoefficiency $[38,51]$. In addition, the strategy of ecoefficiency in agricultural production should focus on improving the quantity of beneficial outputs and reducing harmful outputs to improve environmental performance. Consequently, output variables used for the DEA herein are defined as the beneficial output production per unit of harmful output. The harmful outputs are $\mathrm{NH}_{3}-\mathrm{N}, \mathrm{TN}$, and TP based on examples from previous studies and data availability. Table 2 shows the input-output variables of intensive agricultural production.

4.2. The DMUs. This study assesses the ecoefficiency of intensive agricultural production at the provincial level in China. The provincial administrative divisions in China comprise 34 units including 23 provinces, 4 municipalities, 5 autonomous regions, and 2 special administrative regions. Hong Kong, Macao, and Taiwan are not included in this study 


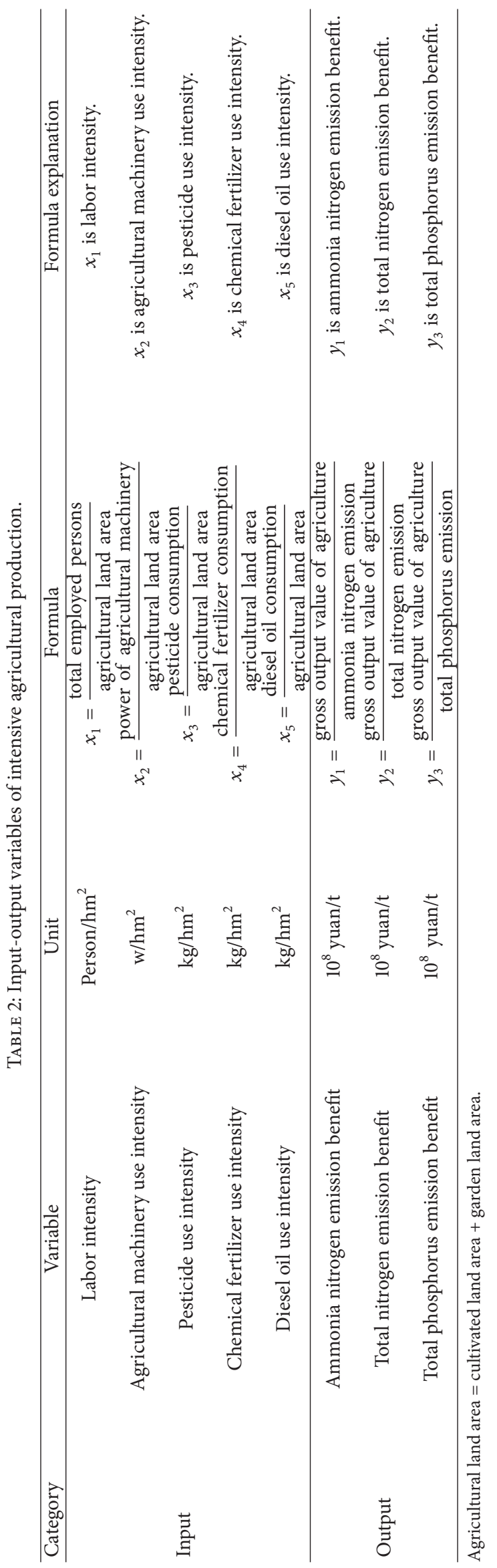


TABLE 3: Statistical description of input-output indicators in 31 provinces.

\begin{tabular}{|c|c|c|c|c|c|c|}
\hline Indicator & Unit & Obs. & Min. & Max. & Mean & Std. dev. \\
\hline Agricultural land area & $10^{3} \mathrm{hm}^{2}$ & 31 & 264.94 & 11890.26 & 4306.67 & 2799.88 \\
\hline Total employed persons & $10^{4}$ persons & 31 & 36.30 & 2711.70 & 909.91 & 694.10 \\
\hline Power of agricultural machinery & $10^{4} \mathrm{kw}$ & 31 & 112.70 & 12419.90 & 3308.36 & 3065.86 \\
\hline Pesticide consumption & $\mathrm{t}$ & 31 & 963.00 & 164812.00 & 57645.19 & 46429.94 \\
\hline Chemical fertilizer consumption & $10^{4} \mathrm{t}$ & 31 & 4.80 & 673.70 & 184.01 & 149.25 \\
\hline Diesel oil consumption & $10^{4} \mathrm{t}$ & 31 & 3.90 & 290.90 & 68.00 & 63.46 \\
\hline Gross output value of agriculture & $10^{8}$ yuan & 31 & 53.40 & 3960.60 & 1514.21 & 1097.84 \\
\hline Ammonia nitrogen emission & $\mathrm{t}$ & 31 & 140.00 & 13737.00 & 4889.19 & 3927.66 \\
\hline Total nitrogen emission & $\mathrm{t}$ & 31 & 1453.00 & 261322.00 & 50908.55 & 53365.31 \\
\hline Total phosphorus emission & $\mathrm{t}$ & 31 & 79.00 & 13730.00 & 3506.90 & 3070.60 \\
\hline
\end{tabular}

due to the absence of original data. The number of DMUs has an important impact on the degree of freedom. Cooper et al. [52] provided a rough rule to solve this problem in DEA model. The guideline is to choose a value of $n$ that satisfies $n \geq \max \{m \times s, 3(m+s)\}$, where $n$ is the number of DMUs, $m$ is the number of inputs, and $s$ is the number of outputs. Therefore the number of DMUs satisfies the rule in this study.

Due to the distinct natural, economic, and social characteristics of the 31 provinces, China is divided into three parts (western, middle, and eastern) according to the 7th FiveYear Plan in China. China's Western Development Program, which aims to narrow the gap between the eastern coast and the western region, has been implemented since 2000. This important policy covers 6 provinces, 5 autonomous regions, and 1 municipality. Therefore, the regionwise partitioning from 7th Five-Year Plan has been adjusted to suit China's Western Development Program. The provinces that compose the three regions in this study are as follows:

The western region in China consists of Inner Mongolia, Guangxi, Chongqing, Sichuan, Guizhou, Yunnan, Tibet, Shaanxi, Gansu, Qinghai, Ningxia, and Xinjiang.

The middle region in China consists of Shanxi, Jilin, Heilongjiang, Anhui, Jiangxi, Henan, Hubei, and Hunan.

The eastern region in China consists of Beijing, Tianjin, Hebei, Liaoning, Shanghai, Jiangsu, Zhejiang, Fujian, Shandong, Guangdong, and Hainan.

4.3. Data Source. The data of the 5 indicators used for assessing ecoefficiency, including power of agricultural machinery, pesticide consumption, chemical fertilizer consumption, diesel oil consumption, and gross output value of agriculture, can be found in China Rural Statistical Yearbook 2013. The data of the 3 harmful output indicators, $\mathrm{NH}_{3}-\mathrm{N}$ emission, TN emission, and TP emission, can also be found in China Environment Yearbook 2013. The agricultural land area data were also collected from China Statistical Yearbook 2013; it is the sum of cultivated land area and garden land. Because the number of total employed persons who were employed in agriculture in 2013 was not available in recent statistical yearbooks, this indicator was collected from China Statistical
Yearbook 2011. The descriptive statistics of indicator values are shown in Table 3.

4.4. Results of Ecoefficiency Analysis in China. Table 4 presents the results of the analysis of ecoefficiency of intensive agricultural production in 31 provinces in China. Only Heilongjiang, Guizhou, Gansu, Qinghai, Ningxia, and Xinjiang can be considered fully efficient, with an ecoefficiency value of 1.000. Fourteen provinces have total efficiencies over 0.500 , which account for approximately $45 \%$ of the 31 provinces. The lowest total efficiency is in Tibet, with the value of 0.205. The technical efficiency values of 11 provinces (Heilongjiang, Guizhou, Gansu, Qinghai, Ningxia, Xinjiang, Inner Mongolia, Liaoning, Shaanxi, Hainan, and Tibet) are 1.000. All the 31 provinces have technical efficiency values greater than 0.400 . The average value of the provinces' technical efficiency is 0.781 . The scale efficiency values of 11 provinces including Heilongjiang, Guizhou, Gansu, Qinghai, Ningxia, and Xinjiang are less than 0.700. Similarly, the technical efficiency values of 17 provinces are less than 0.700 . The average value of scale efficiency for the provinces is 0.693 . There are 15 provinces whose scale efficiency values are lower than their technical efficiency values, and 10 provinces whose scale efficiency values are higher than technical efficiency values (Table 4). Accordingly the average scale efficiency is relatively low in terms of ecoefficiency of intensive agricultural production in China.

The total efficiency may be decomposed into the two parts of technical efficiency and scale efficiency to provide some insight into the source of inefficiency. Poor input utilization leads to a state of technical inefficiency, such that agricultural production cannot achieve maximum potential ecological outputs. Inappropriate scale sizes for input and output that mix in intensive agricultural production result in scale inefficiency. The ecoefficiency results indicate that the low scale efficiency in intensive agricultural production in China is primarily attributed to the low total efficiency instead of a low technical efficiency.

The total efficiency, technical efficiency, and scale efficiency components of ecoefficiency were classified as follows: full efficiency, high efficiency, moderate efficiency, and low efficiency. According to Deng et al. [53] and He et al. [54], classification threshold values of the criteria for ecoefficiency 
TABLE 4: Ecoefficiency of intensive agricultural production in China.

\begin{tabular}{|c|c|c|c|c|}
\hline Province & Total efficiency & Technical efficiency & Scale efficiency & District location \\
\hline Heilongjiang & 1.000 & 1.000 & 1.000 & Middle region \\
\hline Guizhou & 1.000 & 1.000 & 1.000 & Western region \\
\hline Gansu & 1.000 & 1.000 & 1.000 & Western region \\
\hline Qinghai & 1.000 & 1.000 & 1.000 & Western region \\
\hline Ningxia & 1.000 & 1.000 & 1.000 & Western region \\
\hline Xinjiang & 1.000 & 1.000 & 1.000 & Western region \\
\hline Inner Mongolia & 0.934 & 1.000 & 0.934 & Western region \\
\hline Jilin & 0.907 & 0.932 & 0.973 & Middle region \\
\hline Liaoning & 0.881 & 1.000 & 0.881 & Eastern region \\
\hline Shaanxi & 0.707 & 1.000 & 0.707 & Western region \\
\hline Chongqing & 0.687 & 0.909 & 0.756 & Western region \\
\hline Henan & 0.673 & 0.691 & 0.973 & Middle region \\
\hline Sichuan & 0.661 & 0.783 & 0.844 & Western region \\
\hline Shanxi & 0.519 & 0.950 & 0.546 & Middle region \\
\hline Beijing & 0.470 & 0.673 & 0.698 & Eastern region \\
\hline Hunan & 0.455 & 0.473 & 0.962 & Middle region \\
\hline Hubei & 0.357 & 0.632 & 0.565 & Middle region \\
\hline Fujian & 0.354 & 0.584 & 0.606 & Eastern region \\
\hline Shanghai & 0.346 & 0.898 & 0.385 & Eastern region \\
\hline Yunnan & 0.339 & 0.942 & 0.360 & Western region \\
\hline Jiangxi & 0.332 & 0.617 & 0.538 & Middle region \\
\hline Hainan & 0.325 & 1.000 & 0.325 & Eastern region \\
\hline Hebei & 0.324 & 0.468 & 0.691 & Eastern region \\
\hline Jiangsu & 0.317 & 0.496 & 0.640 & Eastern region \\
\hline Guangdong & 0.278 & 0.590 & 0.471 & Eastern region \\
\hline Guangxi & 0.272 & 0.614 & 0.443 & Western region \\
\hline Shandong & 0.251 & 0.411 & 0.611 & Eastern region \\
\hline Anhui & 0.249 & 0.559 & 0.445 & Middle region \\
\hline Tianjin & 0.246 & 0.488 & 0.504 & Eastern region \\
\hline Zhejiang & 0.209 & 0.505 & 0.413 & Eastern region \\
\hline Tibet & 0.205 & 1.000 & 0.205 & Western region \\
\hline
\end{tabular}

TABLE 5: Classification threshold values of the criteria for ecoefficiency of intensive agricultural production.

\begin{tabular}{|c|c|c|c|c|}
\hline \multirow{2}{*}{ Criteria } & \multirow{2}{*}{$\begin{array}{c}\text { Efficient } \\
\text { Full efficiency }\end{array}$} & \multicolumn{3}{|c|}{ Inefficient } \\
\hline & & High efficiency & Moderate efficiency & Low efficiency \\
\hline Total efficiency & 1 & $>0.5$ & $0.3-0.5$ & $<0.3$ \\
\hline Technical efficiency & 1 & $>0.7$ & $0.5-0.7$ & $<0.5$ \\
\hline Scale efficiency & 1 & $>0.8$ & $0.5-0.8$ & $<0.5$ \\
\hline
\end{tabular}

of intensive agricultural production are shown in Table 5. Based on the ecoefficiency values and the classification threshold values of the criteria, the spatial distribution of ecoefficiency is expressed in Figures 1-3.

The provinces whose total efficiencies are fully efficient are mainly located in the western region. The provinces in the eastern region generally have moderate or low total efficiencies except Liaoning, which has a high total efficiency. The agricultural production in the western region is relatively extensive due to natural and economic constraints such as little precipitation and poverty. In contrast, the agricultural production in the eastern and middle regions is relatively intensive considering their high agricultural productivity. It is conventionally accepted that higher inputs could increase agricultural production. However, the results herein reveal that high inputs per unit land in agricultural production do not improve ecoefficiency and are responsible for discharges of vast amounts of pollution. Spatial variations of ecoefficiency among the regions are resulting from the imperfect technical and scale efficiencies in the different regions.

The provinces that have low technical efficiencies are mainly located in the eastern region. And 8 provinces, accounting for $89 \%$ of the provinces with moderate technical efficiencies, are located in the eastern and middle regions. 


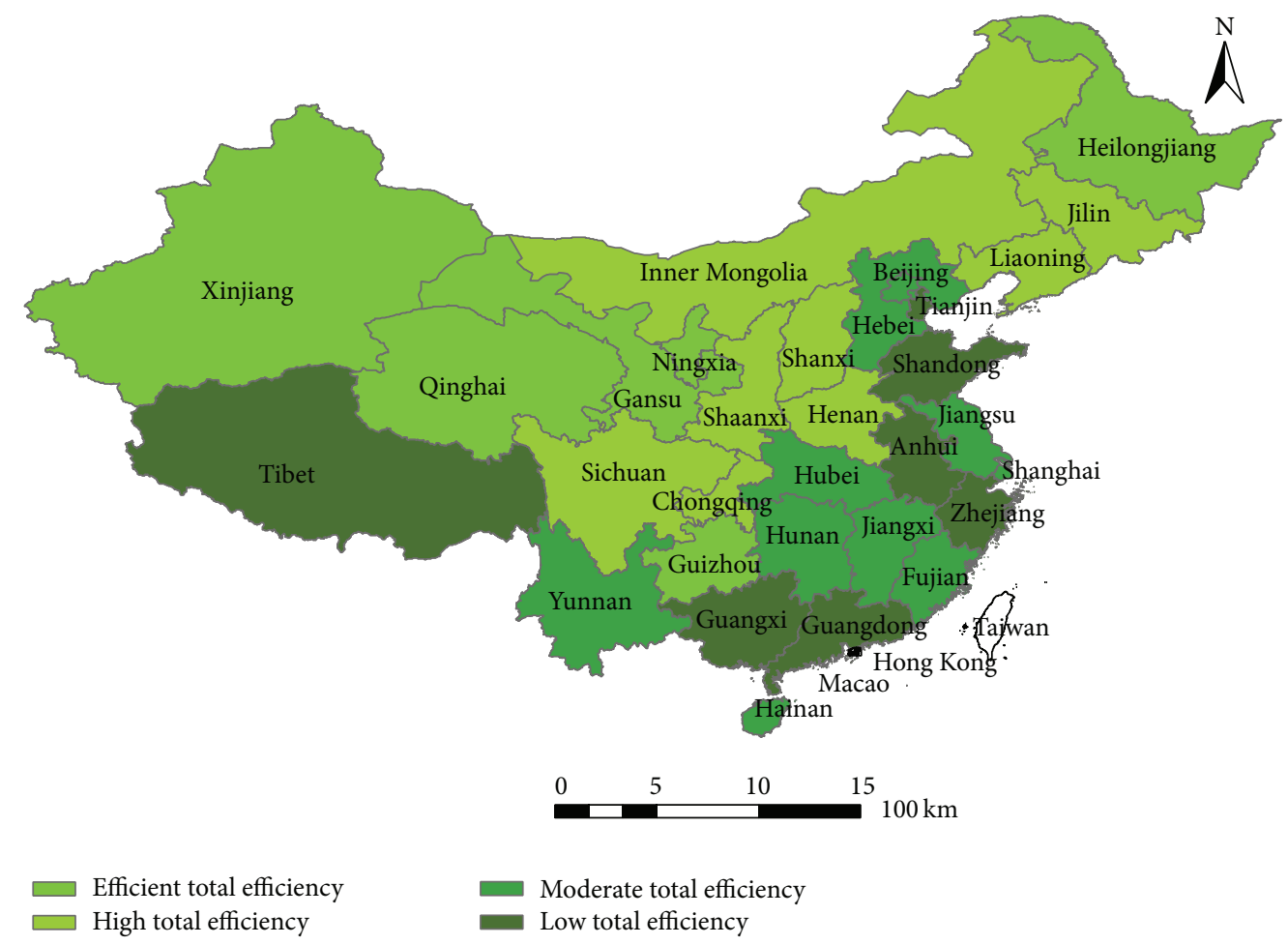

FIGURE 1: Spatial distribution of total efficiency of intensive agricultural production in China.

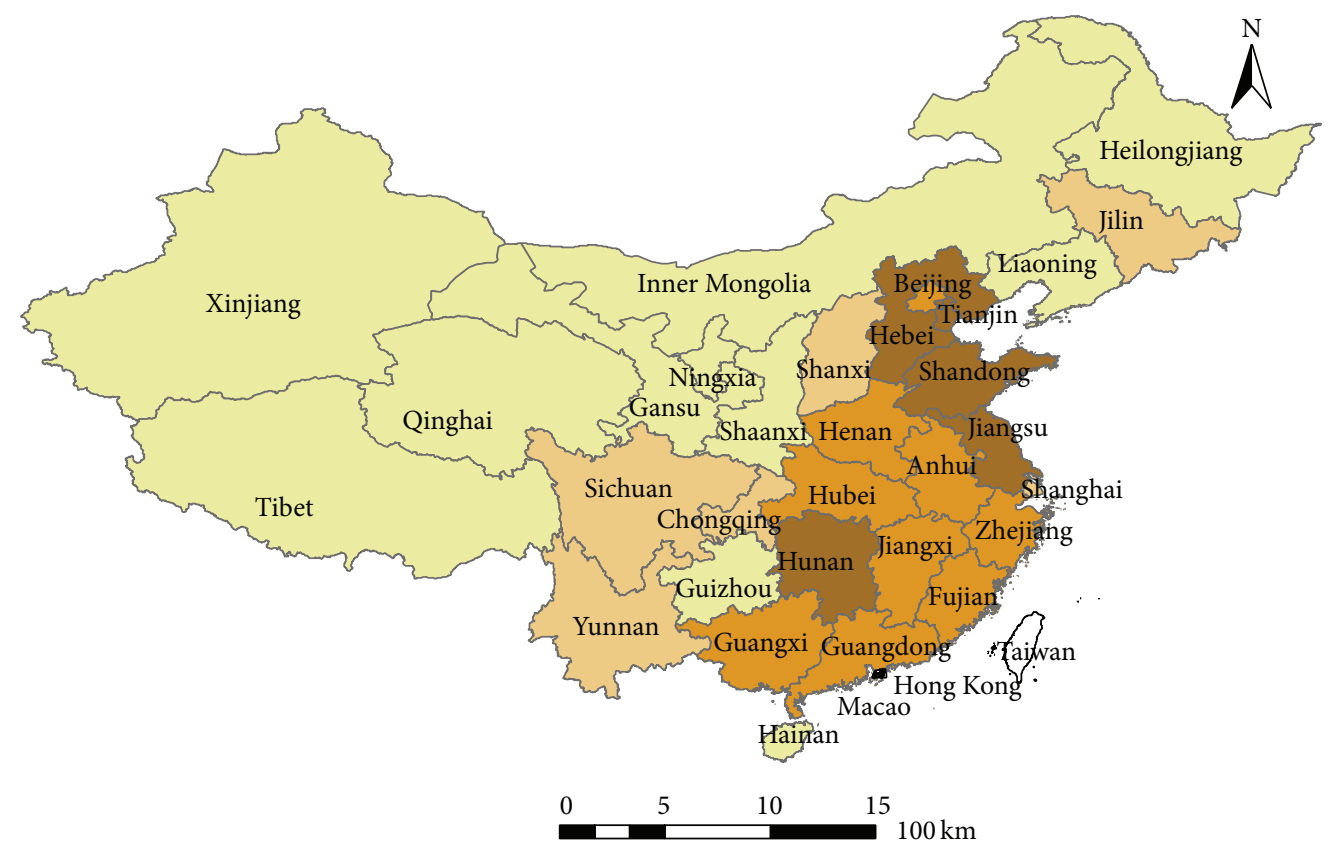

$\begin{array}{ll}\text { Efficient technical efficiency } \\ \text { High technical efficiency } & \text { Moderate technical efficiency } \\ \text { Low technical efficiency }\end{array}$

FIGURE 2: Spatial distribution of technical efficiency of intensive agricultural production in China. 


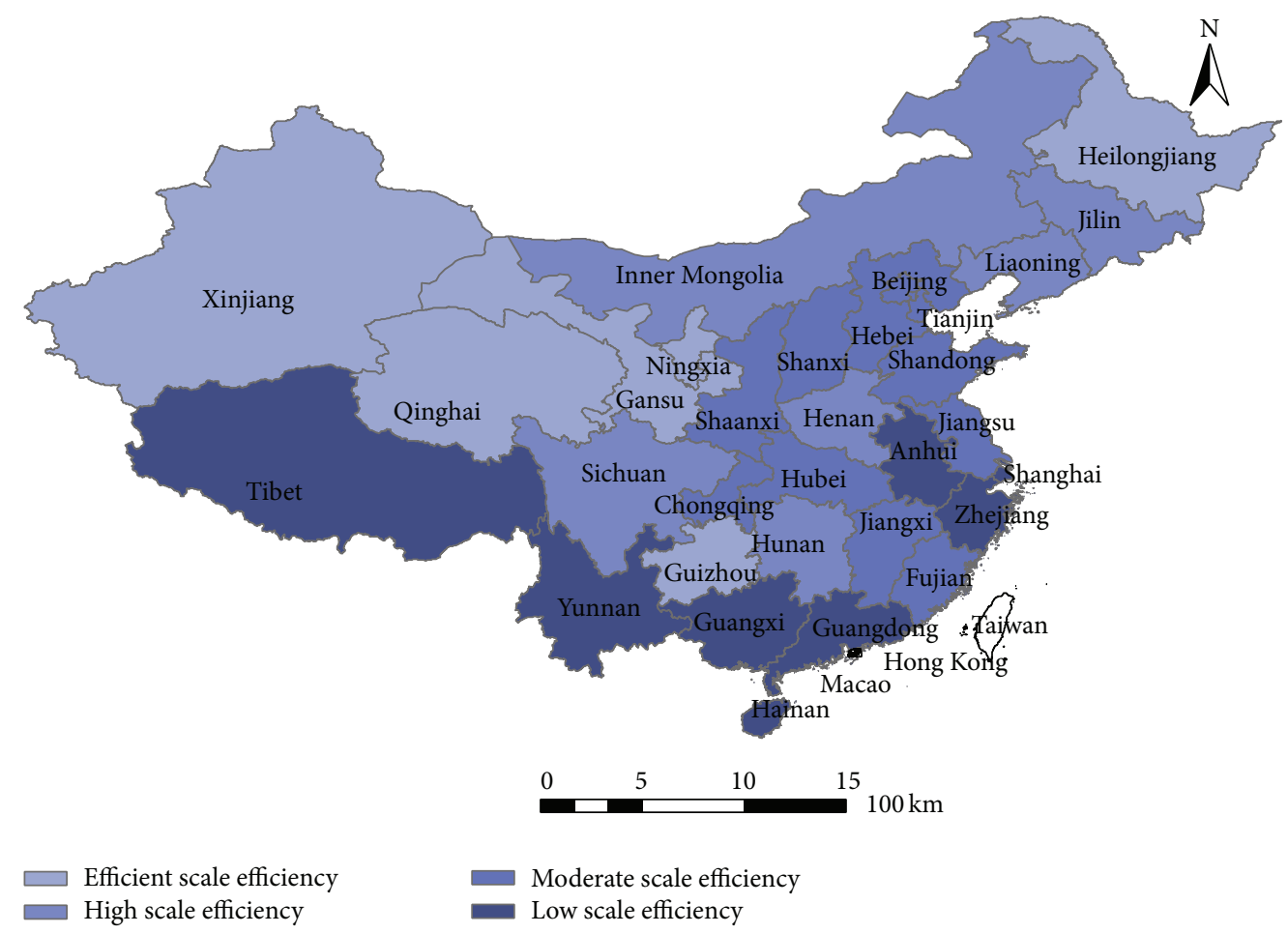

FIGURE 3: Spatial distribution of scale efficiency of intensive agricultural production in China.

However, the technical efficiency in 8 provinces, accounting for $62 \%$ of the provinces located in the western region, can be classified as fully efficient. Moreover, Chongqing, Yunnan, and Sichuan, which are also located in the western region, have high technical efficiencies. The abundance of imperfect technical efficiencies in the eastern and middle regions implies that some inputs in agricultural production, such as labor, agricultural machinery, pesticides, chemical fertilizers, and diesel oil, are inefficiently utilized per unit of agricultural land due to the technology adopted for intensive agricultural production in these areas. The current technology in the eastern and middle regions cannot exploit maximal potential productivity or adequately control the pollution emitted from agricultural production, such as $\mathrm{NH}_{3}-\mathrm{N}, \mathrm{TN}$, and TP.

The imperfect scale efficiencies were distributed across all three regions. Four provinces located in the eastern region, 1 province located in the middle region, and 3 provinces located in the western region have low scale efficiencies. Six provinces located in the eastern region, 3 provinces located in the middle region, and 2 provinces located in the western region have moderate scale efficiencies. Finally, 1 province located in the eastern region, 3 provinces located in the middle region, and 2 provinces located in the western region have high scale efficiencies. However, the contributing factors of the imperfect scale efficiencies in the three regions are different. In the eastern and middle regions, low scale efficiencies are probably a consequence of the inputting of excess resources, such as rising labor intensity, rising pesticide use intensity, rising chemical fertilizer use intensity, and rising diesel oil use intensity, which ultimately raise the output of agricultural production in these regions. The provinces whose scales of agricultural production are nonoptimal locate in the eastern and middle regions, where agricultural production is relatively intensive and input intensity is too high. It can be induced that the output increases in agricultural production are less than proportional to the increases in inputs. In contrast, the provinces whose scales of agricultural production are nonoptimal mainly locate in the western region, where agricultural production is relatively extensive and output intensity is relatively low, suggesting that the inputs do not result in maximal outputs.

\section{Analysis of Factors Influencing Ecoefficiency Based on the Tobit Model}

5.1. Selection of Influential Variables. Peasant household characteristics affect agricultural production behaviors. Therefore, peasant household characteristics also comprise factors that influence ecoefficiency. Education level, land endowment, income features, and family population structure are used to analyze the influence of peasant household characteristics on peasant household behavior [55]. The influential variables of peasant household characteristics selected in this study are shown in Table 6. Economic development also has a significant impact on inputs in agricultural production [12, 56, 57]. Consequently, agriculture's position and industrialization level were also selected as influential variables to reflect the level of economic development. The data of influential variables are from China Rural Statistical Yearbook 2013, China Rural Statistical Yearbook 2013, and China Yearbook of Household Survey 2013. The descriptive statistics of influential variables are shown in Table 7. 
TABLE 6: Influence variables used in Tobit model.

\begin{tabular}{lccc}
\hline & Influence variable & Symbol & Unit or definition \\
\hline & Education level & EL & Year \\
Peasant household characteristics & Farmland area per capita & FA & mu/person \\
& Income per capita & IC & $10^{4}$ yuan/person \\
& Wage percentage & WP & Percent of wage in income \\
& Population per household & PH & Person \\
& Population burden coefficient & PB & Nonlabor force divided by labor force \\
Level of economic development & Agricultural productive fixed assets per household & AF & $10^{4}$ yuan/household \\
& Agriculture's position & AP & Percent of industrial added value in GDP \\
& Industrialization level & IL & Percent of agricultural added value in GDP \\
\hline
\end{tabular}

TABLE 7: Statistical description of influence variables in 31 provinces.

\begin{tabular}{lccccc}
\hline Variable & Obs. & Min. & Max. & Mean & Std. dev. \\
\hline EL & 31 & 4.080 & 10.440 & 8.194 & 1.053 \\
FA & 31 & 0.260 & 13.560 & 2.586 & 3.007 \\
IC & 31 & 0.450 & 1.780 & 0.850 & 0.334 \\
WP & 31 & 0.160 & 0.660 & 0.421 & 0.133 \\
PH & 31 & 2.900 & 5.700 & 3.897 & 0.585 \\
PB & 31 & 1.300 & 1.700 & 1.426 & 0.093 \\
AF & 31 & 0.080 & 2.480 & 0.785 & 0.577 \\
AP & 31 & 0.600 & 24.900 & 10.516 & 5.206 \\
IL & 31 & 7.900 & 50.740 & 40.501 & 9.869 \\
\hline
\end{tabular}

5.2. Results of Influencing Factor Analysis. The effects of influencing factors on ecoefficiency, which consists of total efficiency, technical efficiency, and scale efficiency, are evaluated by using the Tobit model. The results of the Tobit regression are presented in Table 8.

The results show that FA, IC, PH, and PB have statistically significant impacts on the total efficiency component of ecoefficiency. The coefficients for the impacts of FA and PB are positive, but the coefficients for IC and $\mathrm{PH}$ are negative. The different performances of the variables can be revealed from the Tobit regression analysis for technical efficiency and scale efficiency.

FA has a significantly positive impact on technical efficiency and scale efficiency. With a larger farmland area, a peasant may be inclined to adopt advanced technology, which is beneficial to the technical efficiency component of ecoefficiency. Meanwhile, a larger farmland area can also improve scale efficiency. The reason for this improvement is that the increase of farmland area per capita can reduce the mismatch between agricultural input quantity and agricultural output quantity, which consists of beneficial and harmful components. IC significantly affects technical efficiency and scale efficiency negatively. The income per capita is closely related with the capabilities of peasants. However, the more capable and wealthier peasants utilize agricultural input less efficiently in terms of technical efficiency because the technology that the peasants adopt to raise their agricultural outputs, such as grain and vegetables, is not beneficial for controlling the discharge of pollution and waste. Moreover, the income per capita is a negative factor for scale efficiency. This is because the peasants might adopt the excessive use of some agricultural inputs, especially pesticides and chemical fertilizers, to obtain high return. $\mathrm{PH}$ has a significantly negative impact on technical efficiency, but it has no significant impact on scale efficiency. A possible driver of this negative impact is that a peasant household, which consists of many people, tends to substitute labor for new techniques. $\mathrm{PB}$ does not have a significant impact on either technical efficiency or scale efficiency. This means that the effect of population burden on total efficiency relies on the interaction between its effect on technical efficiency and its effect on scale efficiency.

$\mathrm{WP}, \mathrm{AF}$, and IL have significantly negative impacts on technical efficiency but have no significant impact on total efficiency. The main reason for this is that the three variables have an opposite impact on scale efficiency, although the impact is not statistically significant. The growth of wage percent plays a role in worsening technical efficiency because of the limited effect of adopting technologies with high technical efficiency on enhancing wage income. The negative impact of agricultural productive fixed assets per household and industrialization level reveals that China's rural industrialization development and growth of productive fixed assets owned by peasant households do not focus on improving agricultural input utilization efficiency, which can increase beneficial outputs and decrease harmful outputs.

\section{Policy Implications and Methodological Discussion}

Our study moves forward from ecoefficiency analysis of intensive agricultural production to policy discussion. The suitable policies should be designed according to local circumstances that reflect the different features of ecoefficiency across the three regions. According to the results of influencing factor analysis, FA has a significantly positive impact on ecoefficiency in the eastern region. Increasing agricultural land to decrease input intensity can lead to increasing ecoefficiency, but this has not been achieved due to the conversion of agricultural land into nonagricultural uses driven by the political aspirations of local governments in the eastern region. The local governments, which have promoted the rapid development, provide less support for increasing agricultural land to further the development of 
TABLE 8: Tobit regression results of influencing factor analysis.

\begin{tabular}{|c|c|c|c|c|c|c|}
\hline \multirow{2}{*}{ Variable } & \multicolumn{2}{|c|}{ Total efficiency } & \multicolumn{2}{|c|}{ Technical efficiency } & \multicolumn{2}{|c|}{ Scale efficiency } \\
\hline & Coefficient & $P$ & Coefficient & $P$ & Coefficient & $P$ \\
\hline EL & 0.076 & 0.274 & 0.019 & 0.697 & 0.069 & 0.286 \\
\hline FA & $0.066^{* *}$ & 0.021 & $0.037^{*}$ & 0.068 & $0.045^{*}$ & 0.092 \\
\hline IC & $-0.691^{* * *}$ & 0.003 & $-0.486^{* * *}$ & 0.002 & $-0.478^{* *}$ & 0.025 \\
\hline WP & -0.170 & 0.819 & $-0.982^{*}$ & 0.059 & 0.586 & 0.398 \\
\hline $\mathrm{PH}$ & $-0.232^{*}$ & 0.078 & $-0.161^{*}$ & 0.080 & -0.157 & 0.199 \\
\hline $\mathrm{PB}$ & $1.688^{* *}$ & 0.031 & 0.856 & 0.119 & 1.135 & 0.120 \\
\hline $\mathrm{AF}$ & -0.059 & 0.705 & $-0.191^{*}$ & 0.080 & 0.065 & 0.656 \\
\hline AP & -0.017 & 0.234 & -0.021 & 0.135 & -0.003 & 0.843 \\
\hline IL & -0.001 & 0.853 & $-0.011^{* *}$ & 0.005 & 0.004 & 0.393 \\
\hline Constant & -0.814 & 0.591 & 1.567 & 0.139 & -1.031 & 0.465 \\
\hline Log likelihood & 7.601 & & 18.612 & & 9.719 & \\
\hline Avg. log likelihood & 0.243 & & 0.599 & & 0.314 & \\
\hline Schwarz criterion & 0.733 & & 0.020 & & 0.591 & \\
\hline Hannan-Quinn criterion & 0.390 & & -0.323 & & 0.248 & \\
\hline
\end{tabular}

${ }^{*}$ Significant at the $10 \%$ level, ${ }^{* *}$ significant at the $5 \%$ level, and ${ }^{* * *}$ significant at the $1 \%$ level.

agriculture. So the approach to decrease input intensity in the eastern region should remain focused on controlling the consumption of inputs (e.g., labor, agricultural machinery, pesticides, chemical fertilizers, and diesel oil). In particular, owing to the effect of FA and $\mathrm{PH}$, the agricultural labor should be gradually shifted to urban sectors in a novel urbanization push. Such a policy may increase farmland area per capita and decrease population per household. At the same time, agricultural production methods that employ more advanced technology are also proposed for the eastern region. The effect of IL on ecoefficiency implies that the technology that has been widely used in industrialization processes for agriculture does not improve the technology efficiency component of ecoefficiency. In most cases, adopting more advanced technology can help reduce energy consumption and inputs such as chemical fertilizers and pesticides. At the same conditions, it can produce identical agricultural products with decreased emission of pollutants such as $\mathrm{NH}_{3}$ $\mathrm{N}, \mathrm{TN}$, and TP.

FA plays a key role in improving the ecoefficiency in the middle region. Many provinces in the middle region, such as Henan and Hubei, are the important rice production bases in China. These provinces have additional potential land resources suitable for agriculture. Therefore, we can expand agricultural land to decrease input intensity through land consolidation project that exploits nonagricultural land to raise grain production capacity. Meanwhile, when exploiting nonagricultural land, the ecological risk should be taken seriously. In addition, large-scale agriculture suited to locally advantageous agricultural products is a better alternative to family farming, and it can substitute for potential increases in the input consumption of total agricultural land or, more preferably, even decrease the input consumption. The ecofriendly pesticides that are highly effective and have low toxicity offer a potentially useful approach for reducing the adverse effects of pesticides on ecosystems considering the effect of IC on ecoefficiency. The problem of imperfect technology efficiency that is generated through the excess use of chemical fertilizers, particularly $\mathrm{N}$, should be addressed by improving chemical fertilizer use efficiency. Potential solutions to low chemical fertilizer use efficiency might include promoting the development and use of highly efficient fertilizer application technology and implementing price controls on chemical fertilizers.

The western region is an ecologically sensitive and vulnerable area in China. Although FA has a positive impact on ecoefficiency, the mass conversion of nonagricultural land to agricultural land, such as through forest clearance for agricultural land expansion, might damage local ecosystems. Furthermore, the inputs in the western region are relatively extensive. As a consequence, a decrease of input intensity should be integrated with ecological migration from droughtstricken and water-scarce areas. The population and labor base supported by agricultural land should be reduced, which can help avoid the negative impacts of the population per household $(\mathrm{PH})$ and population burden coefficient $(\mathrm{PB})$ on ecoefficiency. In addition, an appropriate amount of agricultural land should be allowed to be fallow as a way to reduce inputs to land in the long term. More importantly, the quantity of desirable agricultural products per unit of agricultural land should be raised; and the promising way to achieve this aim is to use water saving and pollution emission reduction technology that can also increase farmers' income through agricultural production. Therefore, peasant households' agricultural productive fixed assets (AF) that have negative impact on technical efficiency should be adjusted to include water saving and pollution emission reduction technology.

This study also has some limitations that should be mentioned. First, the sample size is relatively small in this study. 
We cannot assess the ecoefficiency of intensive agricultural production at the municipal level in China given the problem of data availability. Further studies should be carried out when more data are available. Second, some harmful outputs, such as heavy metal contamination and pesticide residue, are not considered in the indicator selection of input-output variables. The data relating to agricultural pollution are not published in public in China. Last, ecoefficiency has been criticized for lacking connections to environmental policy instruments. Despite influencing factor analysis done in this study, the insightful policy discussions directly driven by research findings are still difficult. More policy analysis for ecoefficiency should be carried out to help create insightful policy.

\section{Conclusions}

This study proposed the input-oriented CCR and BCC models of DEA to measure the ecoefficiency of intensive agricultural production in China. Specifically, the labor intensity, agricultural machinery use intensity, pesticide use intensity, chemical fertilizer use intensity, and diesel oil use intensity were designed as input variables; $\mathrm{NH}_{3}-\mathrm{N}$ emission benefit, TN emission benefit, and TP emission benefit were designed as output variables. DEA assessment indicated that the inputoutput variables were effective in reflecting the ecoefficiency of intensive agricultural production in China.

The results show that only Heilongjiang, Guizhou, Gansu, Qinghai, Ningxia, and Xinjiang perform as fully efficient in terms of ecoefficiency and that, on average, the scale efficiency is lower than technology efficiency in terms of the ecoefficiency of intensive agricultural production in China. Furthermore, the spatial distribution of the ecoefficiency of intensive agricultural production across China signifies obvious differences between the eastern, middle, and western regions. The results demonstrate that the provinces whose ecoefficiencies are fully efficient are mainly located in the western region. The provinces which have low or moderate technical efficiency are mainly located in the eastern and middle regions. Overall, the technical efficiency in the western region is better than those in the eastern and middle regions. The imperfect scale efficiencies are distributed across all three regions.

Furthermore, the Tobit model was selected to analyze the underlying factors influencing ecoefficiency. The influencing factors analysis shows that FA, IC, PH, and PB have statistically significant impacts on total efficiency. The distinct effects of different variables on total efficiency are caused by the different effects of the variables on technical efficiency and scale efficiency. Finally, this study proposed designs for policies for improving ecoefficiency suitable for different local circumstances, given the different features of ecoefficiency in each of the three regions.

\section{Conflict of Interests}

The authors declare that there is no conflict of interests regarding the publication of this paper.

\section{Acknowledgments}

This research has received financial support by Zhi-Jiang Young Scholar Program of Social Science of Zhejiang Province, by National Natural Science Foundation of China under Grants no. 71403235 and no. 71303203, by Zhejiang Provincial Natural Science Foundation under Grant no. LQ14G030016, and by Youth Key Projects of Humanity and Social Science for Universities of Zhejiang Province under Grant no. 2013QN002.

\section{References}

[1] S. Fan and P. G. Pardey, "Research, productivity, and output growth in Chinese agriculture," Journal of Development Economics, vol. 53, no. 1, pp. 115-137, 1997.

[2] M. Fan, J. Shen, L. Yuan et al., "Improving crop productivity and resource use efficiency to ensure food security and environmental quality in China," Journal of Experimental Botany, vol. 63, no. 1, pp. 13-24, 2012.

[3] S. Yao and Z. Liu, "Determinants of grain production and technical efficiency in China," Journal of Agricultural Economics, vol. 49, no. 2, pp. 171-184, 1998.

[4] D. H. Perkins, Agricultural Development in China, 1368-1968, Aldine Transaction, Piscataway, NJ, USA, 2013.

[5] J. A. Foley, R. DeFries, G. P. Asner et al., "Global consequences of land use," Science, vol. 309, no. 5734, pp. 570-574, 2005.

[6] M. C. Ockenden, C. Deasy, J. N. Quinton, A. P. Bailey, B. Surridge, and C. Stoate, "Evaluation of field wetlands for mitigation of diffuse pollution from agriculture: sediment retention, cost and effectiveness," Environmental Science \& Policy, vol. 24, pp. 110-119, 2012.

[7] E. D. Ongley, Z. Xiaolan, and Y. Tao, "Current status of agricultural and rural non-point source Pollution assessment in China," Environmental Pollution, vol. 158, no. 5, pp. 1159-1168, 2010.

[8] H. You, "Impact of urbanization on pollution-related agricultural input intensity in Hubei, China," Ecological Indicators, vol. 62, pp. 249-258, 2016.

[9] J.-C. Castella, G. Lestrelin, C. Hett et al., "Effects of landscape segregation on livelihood vulnerability: moving from extensive shifting cultivation to rotational agriculture and natural forests in northern Laos," Human Ecology, vol. 41, no. 1, pp. 63-76, 2013.

[10] S. Su and R. Xiao, "Spatially varying determinants of farmland conversion across Qiantang watershed, China," Environmental Management, vol. 52, no. 4, pp. 907-916, 2013.

[11] X. Liu and L. Lynch, "Do agricultural land preservation programs reduce farmland loss? Evidence from a propensity score matching estimator," Land Economics, vol. 87, no. 2, pp. 183-201, 2011.

[12] S. Su, X. Ma, and R. Xiao, "Agricultural landscape pattern changes in response to urbanization at ecoregional scale," Ecological Indicators, vol. 40, pp. 10-18, 2014.

[13] H. You, "Quantifying the coordinated degree of urbanization in Shanghai, China," Quality \& Quantity, 2015.

[14] H. You, "Quantifying megacity growth in response to economic transition: a case of Shanghai, China," Habitat International, vol. 53, pp. 115-122, 2016.

[15] H. You, "Quantifying urban fragmentation under economic transition in Shanghai City, China," Sustainability, vol. 8, no. 1, article 21, 2016. 
[16] R. Tan, V. Beckmann, F. Qu, and C. Wu, "Governing farmland conversion for urban development from the perspective of transaction cost economics," Urban Studies, vol. 49, no. 10, pp. 2265-2283, 2012.

[17] D. Tilman, K. G. Cassman, P. A. Matson, R. Naylor, and S. Polasky, "Agricultural sustainability and intensive production practices," Nature, vol. 418, no. 6898, pp. 671-677, 2002.

[18] T. Kuosmanen and M. Kortelainen, "Measuring eco-efficiency of production with data envelopment analysis," Journal of Industrial Ecology, vol. 9, no. 4, pp. 59-72, 2005.

[19] S. Ma, S. Hu, D. Chen, and B. Zhu, "A case study of a phosphorus chemical firm's application of resource efficiency and ecoefficiency in industrial metabolism under circular economy," Journal of Cleaner Production, vol. 87, pp. 839-849, 2015.

[20] P. J. Korhonen and M. Luptacik, "Eco-efficiency analysis of power plants: an extension of data envelopment analysis," European Journal of Operational Research, vol. 154, no. 2, pp. 437-446, 2004.

[21] C. Basset-Mens, S. Ledgard, and M. Boyes, "Eco-efficiency of intensification scenarios for milk production in New Zealand," Ecological Economics, vol. 68, no. 6, pp. 1615-1625, 2009.

[22] B. Zhang, J. Bi, Z. Fan, Z. Yuan, and J. Ge, "Eco-efficiency analysis of industrial system in China: a data envelopment analysis approach," Ecological Economics, vol. 68, no. 1-2, pp. 306-316, 2008.

[23] D. Maxime, M. Marcotte, and Y. Arcand, "Development of eco-efficiency indicators for the Canadian food and beverage industry," Journal of Cleaner Production, vol. 14, no. 6-7, pp. 636648, 2006.

[24] B. Hollingsworth and P. Smith, "Use of ratios in data envelopment analysis," Applied Economics Letters, vol. 10, no. 11, pp. 733735, 2003.

[25] S. C. Ray and A. Ghose, "Production efficiency in Indian agriculture: an assessment of the post green revolution years," Omega, vol. 44, pp. 58-69, 2014.

[26] S. Ma and H. Feng, "Will the decline of efficiency in China's agriculture come to an end? An analysis based on opening and convergence," China Economic Review, vol. 27, pp. 179-190, 2013.

[27] A. J. Picazo-Tadeo, J. A. Gómez-Limón, and E. Reig-Martínez, "Assessing farming eco-efficiency: a data envelopment analysis approach," Journal of Environmental Management, vol. 92, no. 4, pp. 1154-1164, 2011.

[28] Y. Chih-Hai, L. Wu, and L. Hui-Lin, "Analysis of total-factor cultivated land efficiency in China's agriculture," Agricultural Economics, vol. 56, no. 5, pp. 231-242, 2010.

[29] G. B. Nkamleu, "Productivity growth, technical progress and efficiency change in African agriculture," African Development Review, vol. 16, no. 1, pp. 203-222, 2004.

[30] Y. Lorenzo-Toja, I. Vázquez-Rowe, S. Chenel, D. MarínNavarro, M. T. Moreira, and G. Feijoo, "Eco-efficiency analysis of Spanish WWTPs using the LCA+DEA method," Water Research, vol. 68, pp. 651-666, 2015.

[31] B. Arabi, S. Munisamy, A. Emrouznejad, and F. Shadman, "Power industry restructuring and eco-efficiency changes: a new slacks-based model in Malmquist-Luenberger Index measurement," Energy Policy, vol. 68, pp. 132-145, 2014.

[32] W. W. Cooper, L. M. Seiford, and K. Tone, Data Envelopment Analysis: A Comprehensive Text with Models, Applications, References and DEA-Solver Software, Springer, Berlin, Germany, 2nd edition, 2007.
[33] G. Oggioni, R. Riccardi, and R. Toninelli, "Eco-efficiency of the world cement industry: a data envelopment analysis," Energy Policy, vol. 39, no. 5, pp. 2842-2854, 2011.

[34] Z. Zhu, K. Wang, and B. Zhang, "Applying a network data envelopment analysis model to quantify the eco-efficiency of products: a case study of pesticides," Journal of Cleaner Production, vol. 69, pp. 67-73, 2014.

[35] I. C. Leal Jr., P. A. de Almada Garcia, and M. de Almeida D'Agosto, "A data envelopment analysis approach to choose transport modes based on eco-efficiency," Environment, Development and Sustainability, vol. 14, no. 5, pp. 767-781, 2012.

[36] J. A. Gómez-Limón, A. J. Picazo-Tadeo, and E. Reig-Martínez, "Eco-efficiency assessment of olive farms in Andalusia," Land Use Policy, vol. 29, no. 2, pp. 395-406, 2012.

[37] V.-N. Hoang and M. Alauddin, "Input-orientated data envelopment analysis framework for measuring and decomposing economic, environmental and ecological efficiency: an application to OECD agriculture," Environmental and Resource Economics, vol. 51, no. 3, pp. 431-452, 2012.

[38] Z. Hua, Y. Bian, and L. Liang, "Eco-efficiency analysis of paper mills along the Huai River: an extended DEA approach," Omega, vol. 35, no. 5, pp. 578-587, 2007.

[39] A. Charnes, W. W. Cooper, and E. Rhodes, "Measuring the efficiency of decision making units," European Journal of Operational Research, vol. 2, no. 6, pp. 429-444, 1978.

[40] R. D. Banker, A. Charnes, and W. W. Cooper, "Some models for estimating technical and scale inefficiencies in data envelopment analysis," Management Science, vol. 30, no. 9, pp. 1078$1092,1984$.

[41] D. N. Gujarati, Basic Econometrics, Tata McGraw-Hill Education, New Delhi, India, 2012.

[42] J. Tobin, "Estimation of relationships for limited dependent variables," Econometrica, vol. 26, no. 1, pp. 24-36, 1958.

[43] X. Long, K. Oh, and G. Cheng, "Are stronger environmental regulations effective in practice? the case of China's accession to the WTO," Journal of Cleaner Production, vol. 39, pp. 161-167, 2013.

[44] N. Zhang, A. Hu, and J. Zheng, "Using data envelopment analysis approach to estimate the health production efficiencies in China," Frontiers of Economics in China, vol. 2, no. 1, pp. 1-23, 2007.

[45] A. Kutlar, A. Kabasakal, and M. Sarikaya, "Determination of the efficiency of the world railway companies by method of DEA and comparison of their efficiency by Tobit analysis," Quality \& Quantity, vol. 47, no. 6, pp. 3575-3602, 2013.

[46] Y.-C. Hsu, "The efficiency of government spending on health: evidence from Europe and Central Asia," The Social Science Journal, vol. 50, no. 4, pp. 665-673, 2013.

[47] B. S. Caruso, A. D. O'Sullivan, S. Faulkner, M. Sherratt, and R. Clucas, "Agricultural diffuse nutrient pollution transport in a mountain wetland complex," Water, Air, \& Soil Pollution, vol. 224, article 1695, 2013.

[48] C. Buckley and P. Carney, "The potential to reduce the risk of diffuse pollution from agriculture while improving economic performance at farm level," Environmental Science \& Policy, vol. 25, pp. 118-126, 2013.

[49] J. E. Taylor, S. Rozelle, and A. De Brauw, "Migration and incomes in source communities: a new economics of migration perspective from China," Economic Development and Cultural Change, vol. 52, no. 1, pp. 75-101, 2003. 
[50] K. Liu, J. Qin, B. Zhang, and Y. Zhao, "Physiological traits, yields and nitrogen translocation of ratoon rice in response to different cultivations and planting periods," African Journal of Agricultural Research, vol. 7, no. 16, pp. 2539-2545, 2012.

[51] H. Dyckhoff and K. Allen, "Measuring ecological efficiency with data envelopment analysis (DEA)," European Journal of Operational Research, vol. 132, no. 2, pp. 312-325, 2001.

[52] W. W. Cooper, L. M. Seiford, and J. Zhu, Handbook on Data Envelopment Analysis, vol. 164, Springer, Boston, Mass, USA, 2011.

[53] C. Deng, B. Xie, X. Li, Q. He, and D. Zhu, "Analysis on spatialtemporal change of cultivated land intensive use in Changsha city," Transactions of the Chinese Society of Agricultural Engineering, vol. 28, no. 1, pp. 230-237, 2012.

[54] S. He, P. Pan, and Y. Zhu, "The application of a new model in intensive use evaluation of agricultural land," Journal of Natural Resources, vol. 27, no. 3, pp. 460-467, 2012.

[55] J. D. Van Der Ploeg, "Peasant-driven agricultural growth and food sovereignty," Journal of Peasant Studies, vol. 41, no. 6, pp. 999-1030, 2014.

[56] S. Su, Y. Hu, F. Luo, G. Mai, and Y. Wang, "Farmland fragmentation due to anthropogenic activity in rapidly developing region," Agricultural Systems, vol. 131, pp. 87-93, 2014.

[57] M. Zhou, "An interval fuzzy chance-constrained programming model for sustainable urban land-use planning and land use policy analysis," Land Use Policy, vol. 42, pp. 479-491, 2015. 


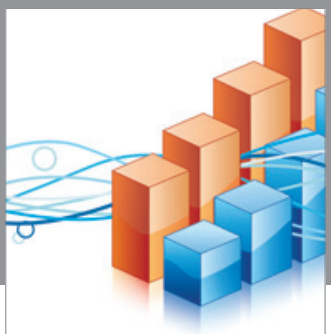

Advances in

Operations Research

vatem alat4

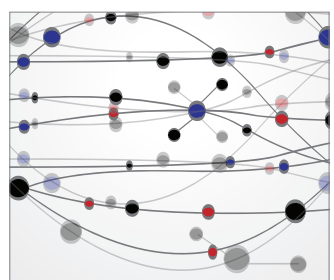

\section{The Scientific} World Journal
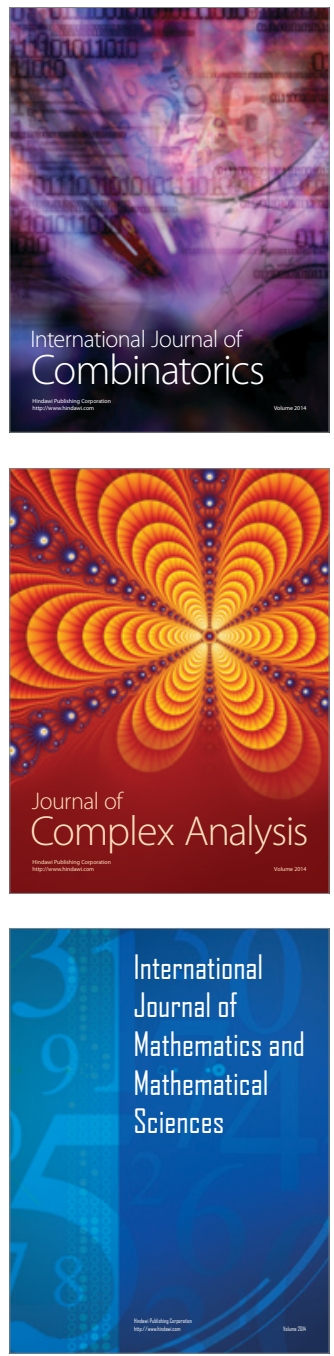
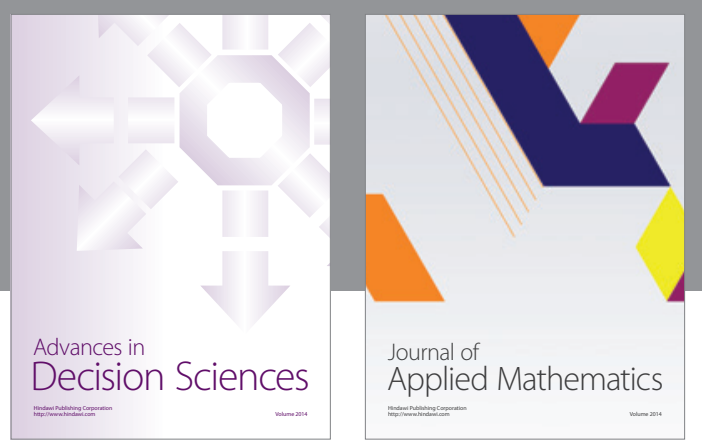

Algebra

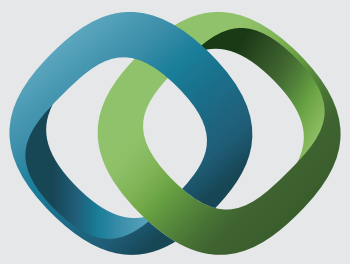

\section{Hindawi}

Submit your manuscripts at

http://www.hindawi.com
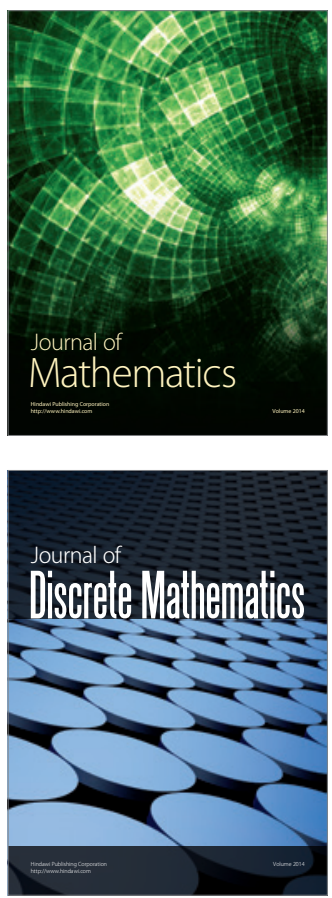

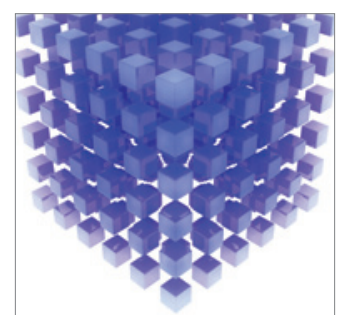

Mathematical Problems in Engineering
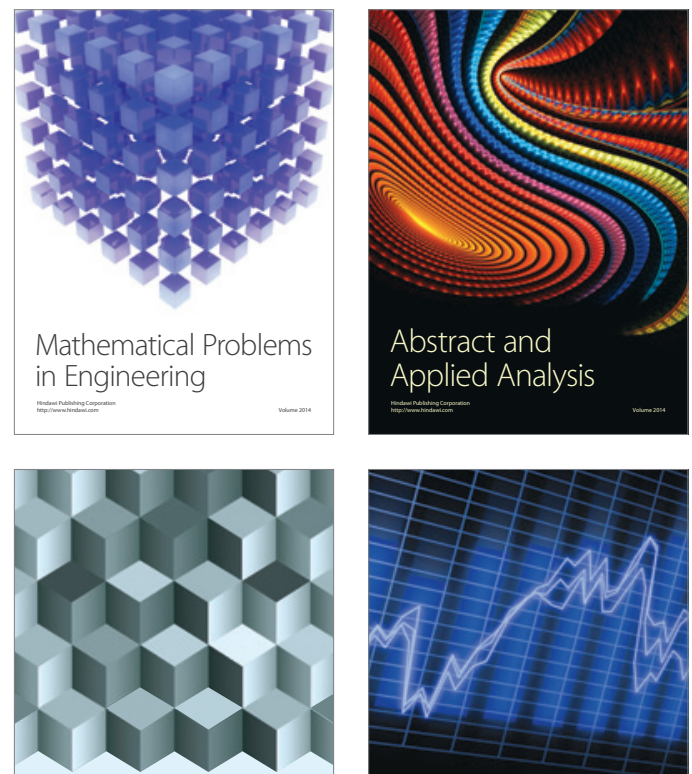

Journal of

Function Spaces

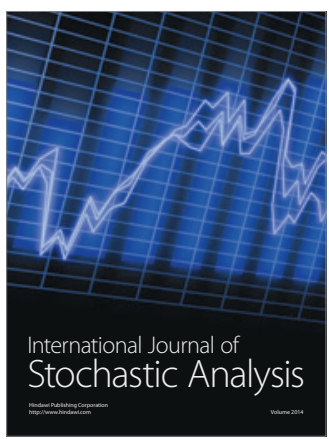

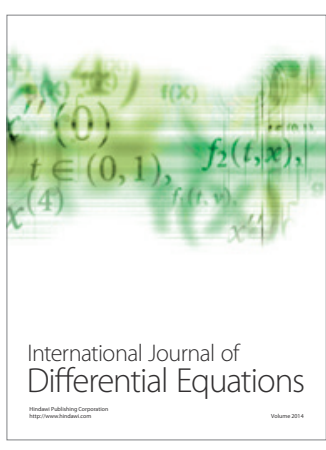
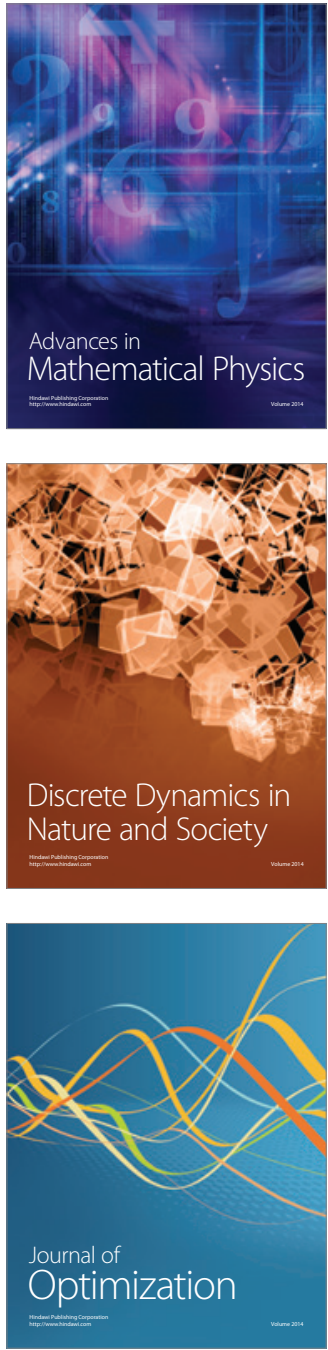